\title{
9
}

\section{Implementing Industry 4.0 in SMEs: A Focus Group Study on Organizational Requirements}

Guido Orzes, Robert Poklemba and Walter T. Towner

\subsection{Introduction}

After the first use of the Industry 4.0 label at the Hannover Fair in 2011, the interest for the topic among managers and policy-makers has grown exponentially. Besides Germany, many countries have launched their own plans to foster the transition toward this new manufacturing

G. Orzes $(\bowtie)$

Faculty of Science and Technology, Free University of Bozen-Bolzano,

Bolzano, Italy

e-mail: guido.orzes@unibz.it

R. Poklemba

Faculty of Manufacturing Technologies, Technical University of Košice,

Prešov, Slovakia

e-mail: robert.poklemba@tuke.sk

W. T. Towner

Center for Innovative Manufacturing Solutions, Worcester Polytechnic Institute, Worcester, USA

e-mail: fabman@wpi.edu

(C) The Author(s) 2020 
paradigm: Plattform Industrie 4.0 (Austria), China 2025, Impresa 4.0 (Italy), Thailand 4.0 just to cite a few examples. Similarly, consultancy companies have exploited the trend, publishing a wide set of reports on Industry 4.0 (see Rüßmann et al. 2015; McKinsey Digital 2015; Geissbauer et al. 2016; among others). While a clear-cut definition of the phenomenon is still missing (Culot et al. 2018), authors agree that Industry 4.0 is based on the application of cyber-physical systems (CPS) and internet technologies in the manufacturing processes, leading to a convergence between the physical and the virtual world (Kagermann et al. 2013).

Over the last few years, the number of scientific papers on Industry 4.0 has significantly grown (Liao et al. 2017). The literature has shown that Industry 4.0 also offers significant opportunities to small- and medium-sized enterprises (SMEs) which can use these technologies to increase their flexibility, productivity, and competitiveness (Kagermann et al. 2013; Wenking et al. 2016). At the same time, this industrial revolution brings some challenges regarding data security, finding the needed capital, developing a strategy for implementing it and finding qualified employees (Schröder 2016). Extant research has, however, mainly focused on technical aspects of Industry 4.0 (Liao et al. 2017). Consequently, a detailed analysis of the implementation strategies, barriers faced, as well as on the organizational requirements, is missing (Holmström et al. 2016).

This chapter aims, therefore, to address the aforementioned research gap by empirically investigating the main organizational issues faced by SMEs in Industry 4.0 implementation. We focus on SMEs for various reasons: (a) they are the backbone of economies of many European countries; (b) they are expected to face more difficulties in adopting Industry 4.0 than large firms due to the lack of resources and knowledge (Müller et al. 2017; Sandberg and Aarikka-Stenroos 2014); but (c) they can more easily change toward the Industry 4.0 paradigm if a suitable roadmap is available (due to their higher flexibility; Mohnen and Rosa 2002).

We first analyze the existing Industry 4.0 literature. This allows us to highlight a set of potential organizational issues for Industry 4.0 implementation, such as the lack of skilled employees, the lack of monetary 
resources, and the lack of a systematic approach for implementation. In order to verify whether additional issues should be considered, we also analyzed the broader literature on the barriers to innovation. We concluded that while the extant literature provides some interesting results, it is still characterized by a significant set of gaps and limitations.

In order to refine and empirically validate the set of organizational issues in Industry 4.0 implementation, we then organized some focus groups in four different countries within the research project SME 4.0, funded by the European Commission (H2020 program). These focus groups lasted one full working day each and involved 13-25 CEOs or technical managers of 7-10 SMEs each, who were asked, after a small introduction about the topic, to write on post-its and discuss several issues they faced during Industry 4.0 adoption and implementation.

Our empirical analyses (focus groups) confirmed most of the organizational requirements identified by previous literature. They also allowed us to highlight a set of additional requirements not considered by previous studies. Our study has, therefore, significant implications for researchers, managers, and policy-makers working in the Industry 4.0 field.

The chapter is organized as follows. In Sect. 9.2, we summarize the two relevant streams of study for our work: (a) organizational issues in Industry 4.0 implementation and (b) barriers and problem for innovation. In Sect. 9.3, we formulate the problem and in Sect. 9.4, we explain the adopted methodological approach. Results are then presented in Sect. 9.5 and discussed in Sect. 9.6. Finally, we summarize the contributions to management theory and practice as well as the main limitations in Sect. 9.7.

\subsection{Background}

In this section, we summarize two main streams of studies that are of interest for our research: (1) organizational obstacles and barriers for Industry 4.0 implementation and (2) barriers for innovation. Despite the second stream of studies not being focused on Industry 4.0, we considered it to analyze whether general barriers to innovation apply also to Industry 4.0 (which is based on a set of innovations). 


\subsubsection{Organizational Barriers to Industry 4.0 Implementation}

In order to identify all the relevant papers dealing with organizational obstacles and barriers for Industry 4.0 implementation, we performed a keyword search in the most important electronic database (Elsevier's Scopus). We used a combination of two sets of keywords:

a. Industry 4.0-related terms (e.g., industry 4.0, industrial internet, fourth industrial revolution, $4^{\circ}$ industrial revolution, Internet of Things, Smart manufacturing, cyber-physical production systems); and b. Barrier-related terms (barrier*, obstacle*, challenge*, problem*, $\mathrm{SME}^{*}$, small and medium enterprise*).

This keyword search led us to identify 6029 contributions. After this search, we applied a set of inclusion-exclusion criteria to screen the papers based first on the title and abstract and then on the full text. In greater detail, we excluded papers that do not provide insights on the obstacles and barriers in Industry 4.0 implementation and which were written in other languages than English and German (we included papers in German as the Industry 4.0 concept was initially conceptualized in this country). The final sample consisted of 17 papers. We added to this sample two additional works by consultancy companies and international organizations since they provided relevant inputs for our study (World Economic Forum 2014; IBM 2015). We finally coded the papers based on the obstacles/barriers highlighted.

The results of the literature review are summarized in Table 9.1, in which we also highlight the type of finding (i.e., conceptual vs. supported by empirical data) and the language of the paper (English vs. German). We identified a total of 19 obstacles/barriers that were classified into 6 categories:

- Economiclfinancial (high investments required, lack of monetary resources, lack of clearly defined economic benefits)

- Cultural (lack of support by top management; preferred autonomy) 


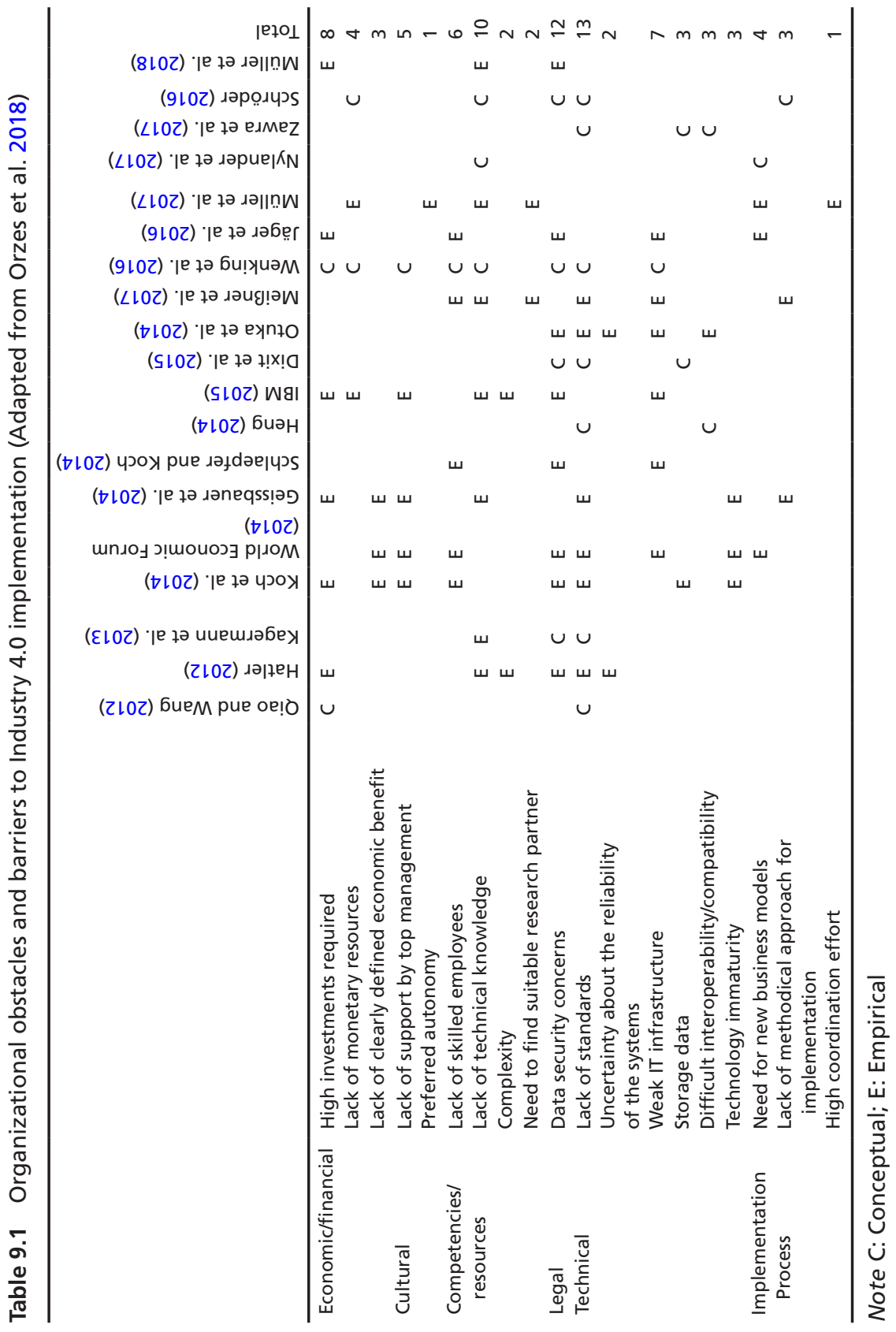


- Competencies/resources (lack of skilled employees, lack of technical knowledge; complexity of the Industry 4.0 application both technical and practical, need to find suitable research partner)

- Legal (data security concerns)

- Technical (lack of standards, uncertainty about the reliability of the systems, weak IT infrastructure, difficult interoperability/compatibility, technology immaturity)

- Implementation process (need for new business models, lack of methodical approach for implementation, high coordination effort).

Authors point out that Industry 4.0 has created some opportunities for SMEs which can use these technologies to increase their flexibility, productivity, and competitiveness (e.g., Kagermann et al. 2013; Wenking et al. 2016). They also emphasize, however, that in order to obtain such benefits, high investments are often required (Hatler 2012; IBM 2015). Sometimes it is therefore not easy, in particular for SMEs, to see the potential economic benefits of Industry 4.0 adoption (Koch et al. 2014; World Economic Forum 2014). A need therefore exists to assess results (such as increase in flexibility, productivity, and market competitiveness) in order to then measure the return on the investment (ROI).

Schröder (2016) argues that Industry 4.0 brings many opportunities but also some significant requirements: data security, finding the needed monetary resources, developing an implementation approach, and finding skilled employees. This sentence is confirmed by our literature review, in which data security appeared as a significant issue with which companies must deal in implementing Industry 4.0. To overcome this issue, standards in cryptography and security models should be developed (Kagermann et al. 2013), since with the extension of the boundaries of the company, the traditional security systems are no longer sufficient (Chen and Zhao 2012).

The development of standards and legal regulations is also essential (Wenking et al. 2016). They should be developed not only to address security concerns, but also for the rapid implementation and diffusion of Industry 4.0. Companies tend, in fact, to work on their own solutions (Wenking et al. 2016) also because there is often the fear-due 
to a lack of trust existing - that sharing knowledge with other companies can reduce profitability (Müller et al. 2017). Such a lack of standards leads, however, to very complex interoperability and compatibility between machines, companies, and infrastructures.

Finally, despite the huge number of articles published on Industry 4.0 , the attention that has been given so far to the development of implementation models is not sufficient (Liao et al. 2017). Three articles in Table 9.1 mention indeed that a methodical approach for implementation is missing (Geissbauer et al. 2014; Meißner et al. 2017; Schröder 2016). To overcome this obstacle, companies need to cooperate and work together to develop compatible automation solutions, which will result in modular factory structures (Weyer et al. 2015).

\subsubsection{Barriers to Innovation}

The success of SMEs is strictly related to their capacity to deal with innovation. Companies that successfully incorporate innovation in their business strategy actually increase productivity and competitiveness (Cefis and Marsili 2006). The other side of the medal is that in the implementation process of (radical) innovation, companies must face several organizational obstacles and challenges, the so-called innovation barriers (IB) (e.g., D'Este et al. 2012; Madrid-Guijarro et al. 2009).

Considering that the adoption of Industry 4.0 can, to some extent, be considered a radical innovation (since it might imply a significant modification of processes, relationships with the customers and the suppliers, value proposition, or even of the business model), we believed it useful to consider in our literature review not only the papers focusing on organizational obstacles and barriers for Industry 4.0 implementation but also the broader stream of studies on organizational barriers to innovation. Considering the wide number of studies on this topic and its lower centrality to our analysis, we started from two recent reviews (Sandberg and Aarikka-Stenroos 2014; Madrid-Guijarro et al. 2009) rather than conducting a new keyword search. 
Table 9.2 Organizational barriers to innovation

\begin{tabular}{|c|c|c|}
\hline Category & Barrier & Exemplary references \\
\hline \multirow{3}{*}{$\begin{array}{r}\text { Economic/ } \\
\text { financial }\end{array}$} & Lack of monetary resources & Kelley (2009) \\
\hline & High investments required & $\begin{array}{l}\text { Martinez and Briz (2000) and } \\
\text { Frenkel (2003) }\end{array}$ \\
\hline & $\begin{array}{l}\text { Innovation cost difficult to } \\
\text { control }\end{array}$ & $\begin{array}{l}\text { Hadjimanolis (1999) and Martinez } \\
\text { and Briz (2000) }\end{array}$ \\
\hline \multirow[t]{8}{*}{ Cultural } & $\begin{array}{l}\text { Lack of support from } \\
\text { customer/supplier }\end{array}$ & $\begin{array}{l}\text { Hewitt-Dundas (2006) and Mohen } \\
\text { and Roller (2005) }\end{array}$ \\
\hline & Unsupportive government & Hadjimanolis (1999) and Freel (2000) \\
\hline & Paucity of external finance & Minetti (2010) \\
\hline & Excessive risk & $\begin{array}{l}\text { Hewitt-Dundas (2006) and Galia and } \\
\text { Legros (2004) }\end{array}$ \\
\hline & Preferred autonomy & Lynn et al. (1996) \\
\hline & $\begin{array}{l}\text { Unsupportive organiza- } \\
\text { tional structure }\end{array}$ & $\begin{array}{l}\text { Baldwin and Lin (2002) and } \\
\text { Martinez and Briz (2000) }\end{array}$ \\
\hline & Restrictive mindset & Wolfe et al. (2006) \\
\hline & Restrictive local culture & Riffai et al. (2012) \\
\hline Technical & Technological immaturity & Chiesa and Frattini (2011) \\
\hline \multirow{6}{*}{$\begin{array}{l}\text { Lack of } \\
\text { competen- } \\
\text { cies }\end{array}$} & $\begin{array}{l}\text { Lack of discovery } \\
\text { competencies }\end{array}$ & O'Connor and DeMartino (2006) \\
\hline & $\begin{array}{l}\text { Lack of incubation } \\
\text { competencies }\end{array}$ & O'Connor and DeMartino (2006) \\
\hline & $\begin{array}{l}\text { Lack of acceleration } \\
\text { and commercialization } \\
\text { competencies }\end{array}$ & $\begin{array}{l}\text { O'Connor and DeMartino (2006) } \\
\text { and Story et al. (2009) }\end{array}$ \\
\hline & $\begin{array}{l}\text { Lack of qualified } \\
\text { employees }\end{array}$ & $\begin{array}{l}\text { Mohen and Roller (2005) and Galia } \\
\text { and Legros (2004) }\end{array}$ \\
\hline & $\begin{array}{l}\text { Lack of information about } \\
\text { technologies }\end{array}$ & $\begin{array}{l}\text { Galia and Legros (2004) and Frenkel } \\
\text { (2003) }\end{array}$ \\
\hline & $\begin{array}{l}\text { Inappropriate } \\
\text { infrastructure }\end{array}$ & lyer et al. (2006) \\
\hline
\end{tabular}

We identified 18 barriers that we brought back to the categories already introduced for the organizational barriers and obstacles in Industry 4.0 implementation (see Table 9.2).

One of the common problems in technological changes are economic/financial issues, especially for SMEs (Sandberg and AarikkaStenroos 2014; Mohnen and Rosa 2002). This has been confirmed by the review both on innovation and on Industry 4.0 (see Tables 9.1 and 9.2). Cultural issues (e.g., unsupportive organizational structure, 
restrictive mindset, and preferred autonomy) also play an important role in the introduction of new practices. Wolfe et al. (2006) emphasize that the resistance to change is due to the fact that innovation brings changes, which generate in the employees the fear of losing their job.

One barrier highlighted for innovation, but not for Industry 4.0 implementation, is the unsupportive government. This might be explained by the fact that many governments have launched significant investment plans to support the transition toward Industry 4.0. We have already mentioned in the introduction section the Italian plan Impresa 4.0, the Austrian Plattform Industrie 4.0, China 2025, and Thailand 4.0.

\subsection{Problem Formulation}

Extant Industry 4.0 literature has shed light on a wide set of organizational barriers and problems in Industry 4.0 implementation (see Sect. 9.2.1). The literature is, however, characterized by at least two significant limitations. First, most papers (58\%) are published in conference proceedings or reports (not subject to a rigorous peer-review process). Second, if we compare the list of barriers highlighted in Industry 4.0 literature (see Table 9.1) with the broader set of barriers in innovation adoption highlighted by the innovation management literature (see Table 9.2), we notice that various barriers are missing in Industry 4.0 literature (such as the unsupportive government and excessive risks). The comprehensiveness of the list of barriers to Industry 4.0 identified by extant literature is therefore called into question.

The aim of this chapter is therefore to identify through a rigorous empirical analysis the main organizational barriers and issues faced by SMEs in Industry 4.0 implementation, in order to find possible solutions to the identified barriers and to propose some directions for future research. This represents a fundamental step toward the diffusion of Industry 4.0 among SMEs. 


\subsection{Methodology}

\subsubsection{Focus Group Method}

Considering the novelty of the topic and the need for an in-depth exploration (Stewart and Shamdasani 1990), we adopted the focus group methodology. This research method, which was developed in medical and marketing research, is now frequently used as well in social sciences research (Parker and Tritter 2006). It has been argued to be particularly suitable for providing trustworthy insights about human behavior based on naturalistic data (Grudens-Schuck et al. 2004) and therefore, fits very well with the goals of our paper (i.e., to shed light on the organizational issues faced by SMEs in Industry 4.0 implementation).

Focus groups are typically composed of small groups of 5-12 people, in order to give everyone a chance to express his/her opinion about the topic (Krueger and Casey 2000). The participants have similar characteristics, like the knowledge of the topic or the field, so that they can provide quality data in a focused discussion. In order to be defined as a focus group, the discussion needs to have the following five characteristics: (1) participants should have similar characteristics (e.g., job role, experience, and/or culture); (2) the group should be small; (3) there should be the presence of a moderator (often a researcher; Morgan and Spanish 1984) to keep the group "focused" and generate a productive discussion; (4) the interaction among participants should be allowed; and (5) the topic should be presented before asking the questions (Krueger and Casey 2000). One of the advantages of this methodology is that it can encourage contributions from people who initially feel they have nothing to say but then participate in the discussion generated by other members of the group (Kitzinger 1995).

Four focus groups (lasting one full working day each) were organized in Italy, Austria, USA, and Thailand under the EU research project 'SME 4.0 - Industry 4.0 for SMEs'. These focus groups were scheduled on different days but in the same period and the attendees took part in them physically (not through video conferences). A standardized protocol for the focus groups was defined in order to guarantee comparability of the findings (see Sect. 9.4.2). 


\subsubsection{Sample Selection and Data Collection}

Each focus group was attended by $13-25$ CEOs or managers of 7-10 SMEs belonging to different manufacturing sectors, including electronics, industrial and agricultural equipment, furniture, and metal carpentry. Having an overview over different manufacturing sectors allowed us to identify the general issues in the implementation of Industry 4.0 in SMEs, independently from the specific sector of the company.

The reason why CEOs and technical managers were invited is that they have an overall knowledge about the topic and about the problems their company face when introducing changes in its organizational structure.

After a brief introduction by the researchers about Industry 4.0 and related concepts, the participants took part in some brainstorming sessions in which they were asked to reflect on various topics related to Industry 4.0 implementation: (1) adaptable manufacturing systems design; (2) intelligent manufacturing through information and communication technology (ICT) and cyber-physical systems (CPS); (3) automation and human-machine interaction; and (4) main barriers and difficulties for SMEs. During these sessions, the participants also wrote, on some post-its, the most important issues. After these brainstorming sessions, the issues which emerged were then discussed in detail among the participants.

\subsubsection{Data Analysis}

The data which emerged from the four focus groups were then coded by two researchers among the authorial team. We identified 108 elementary barriers and problems in Industry 4.0 implementation, which were then manually screened to check their validity. Five barriers were eliminated at this stage since they were not clear or too general (i.e., SMEs' risk of losing the lead, missing automated measuring systems; solving, problems when problems are over; culture $\rightarrow$ people base; technology based; lack of systems to prevent bottlenecks in single point of failure production line). 
We then classified the barriers according to the six categories already introduced in the literature review section (economiclfinancial, cultural, competencies/resources, legal, technical, and implementation process) and reported all the results of the four countries in a single table (see Table 9.3). In such a table, we also specified if the barrier was already highlighted by previous studies both on Industry 4.0 (I4.0) and on IB, in order to have a clear idea of what is new and what is already present in the existing literature. Some barriers were assigned to more than one category since they included two or more concepts. For instance, the barrier high investments with uncertain ROI refers both to high investments required (high investments) and to lack of clearly defined economic benefits (uncertain ROI). Similarly, the barrier product characteristics was included both in the economic/financial and in the implementation process category since in one case, the workshop participants emphasized that for low value-added products the investment in Industry 4.0 is not worthwhile, while in the other case, they highlighted that during the implementation, it is sometimes not easy to combine the need for high flexibility with higher automated processes.

The final list consisted of 103 organizational barriers and problems in Industry 4.0 adoption. These barriers will be analyzed in detail in Sect. 9.5.

\subsection{Results}

The focus groups highlighted several barriers and problems for Industry 4.0 implementation in SMEs (see Table 9.3). As mentioned above, we classified them according to the six categories used in the literature review (economic/financial, cultural, competencies/resources, legal, technical, and implementation process).

Most of the participants in the four countries pointed out that the investments required for the implementation of Industry 4.0 are very high, both in terms of money and time required. Italian and Thai managers and CEOs emphasized that not only are the required investments high, but also that the ROI is often not very clear. This can be due to the unclear potential of the different technologies or to the difficulties 


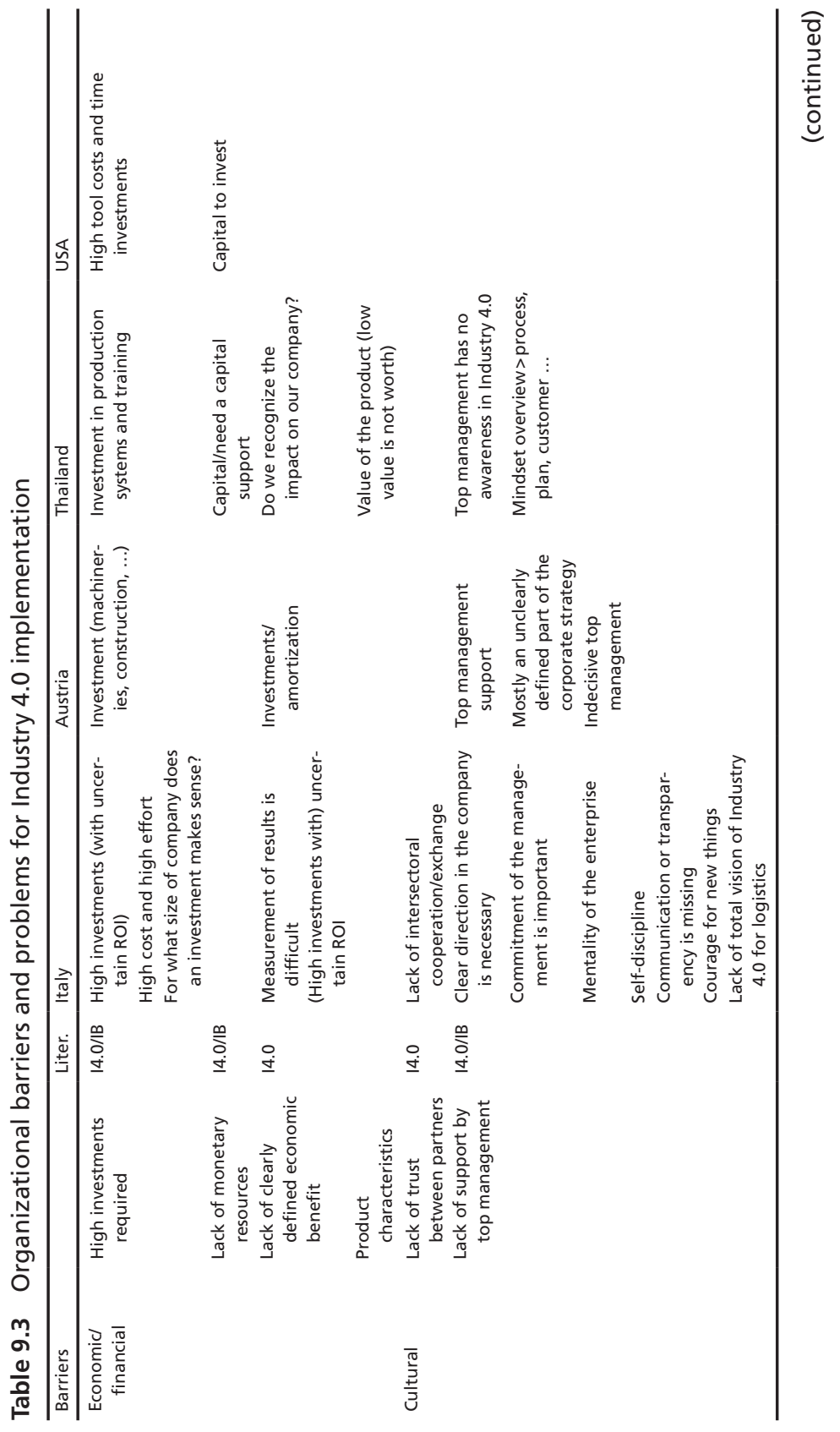




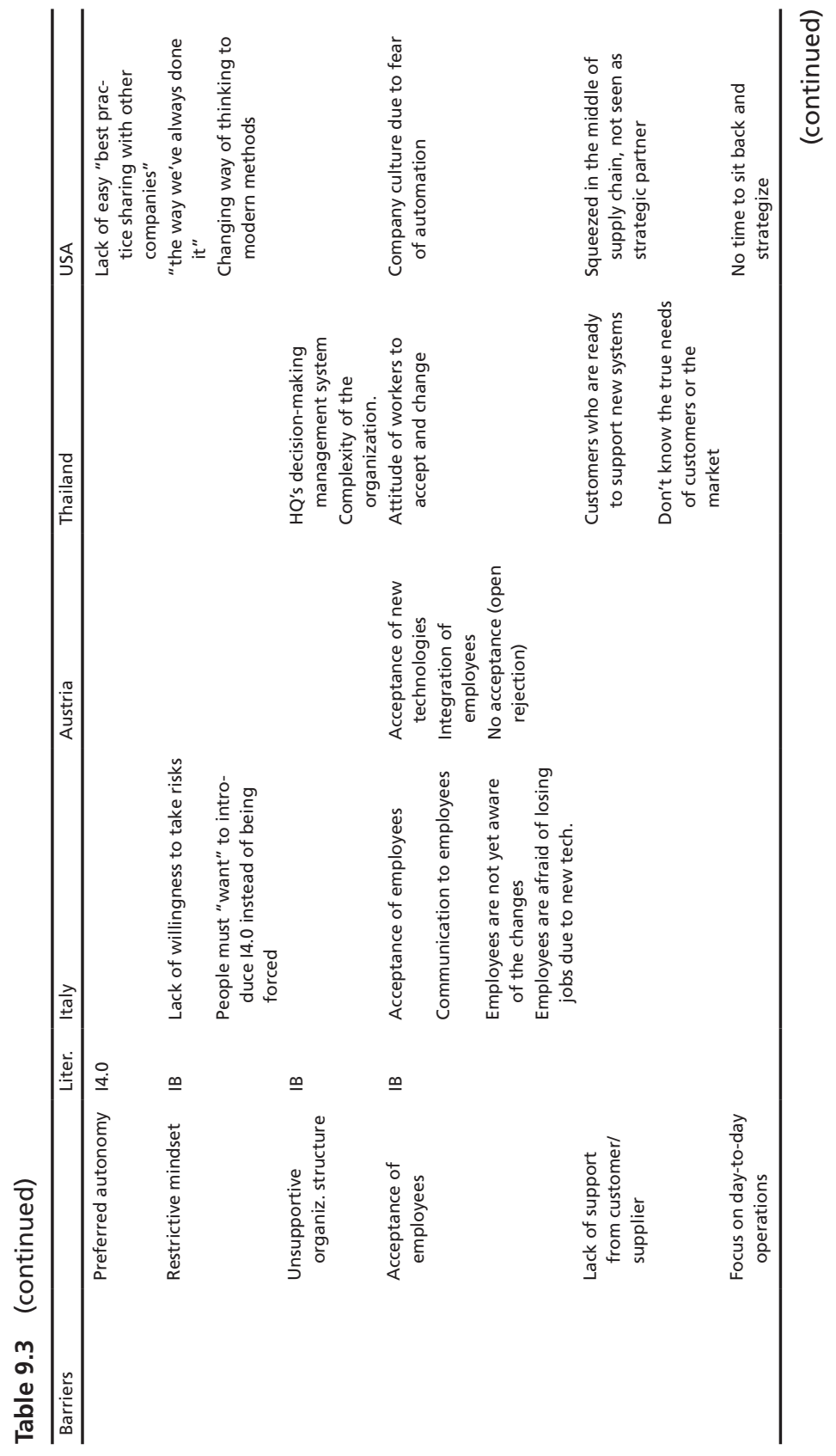




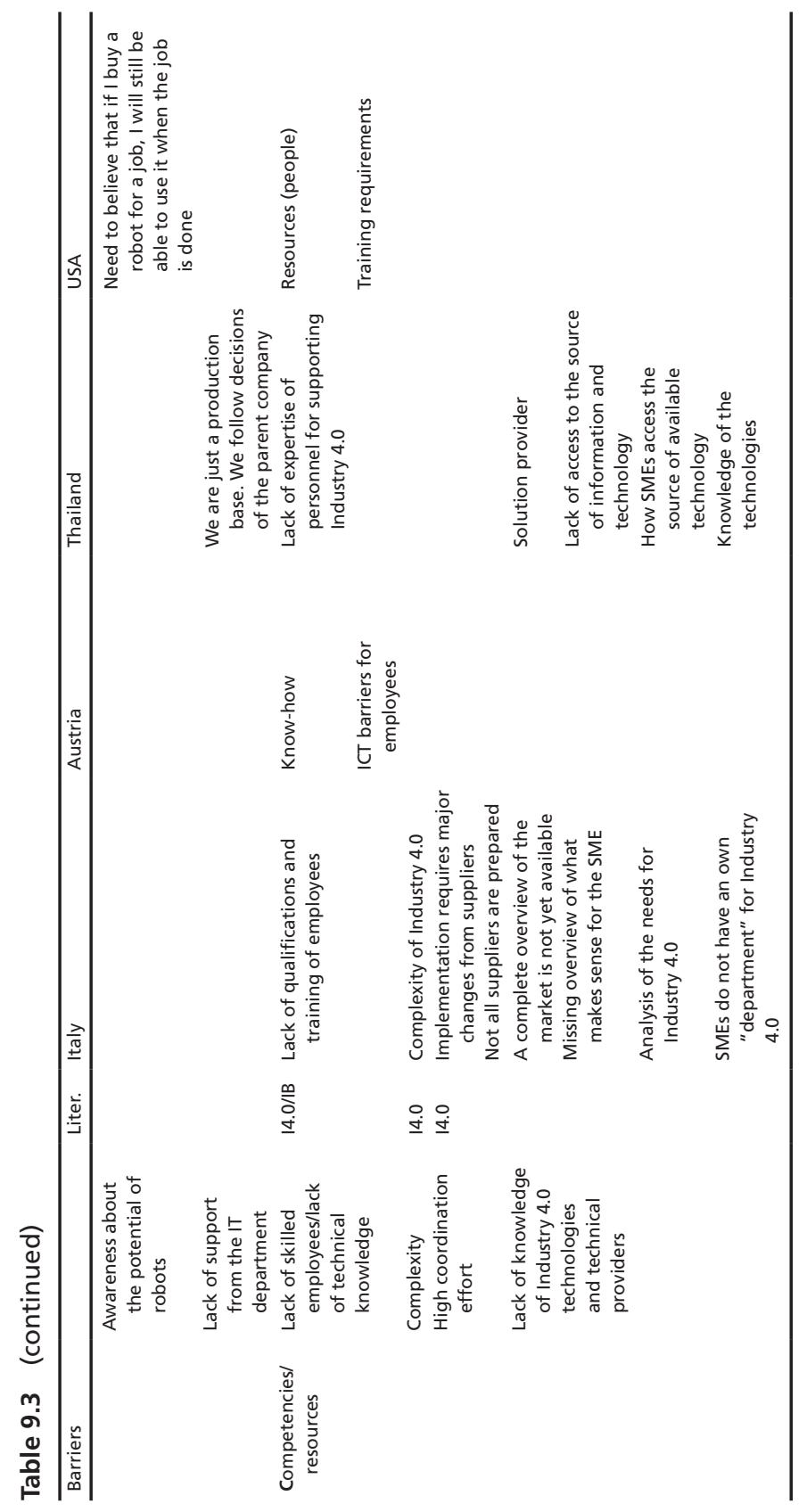




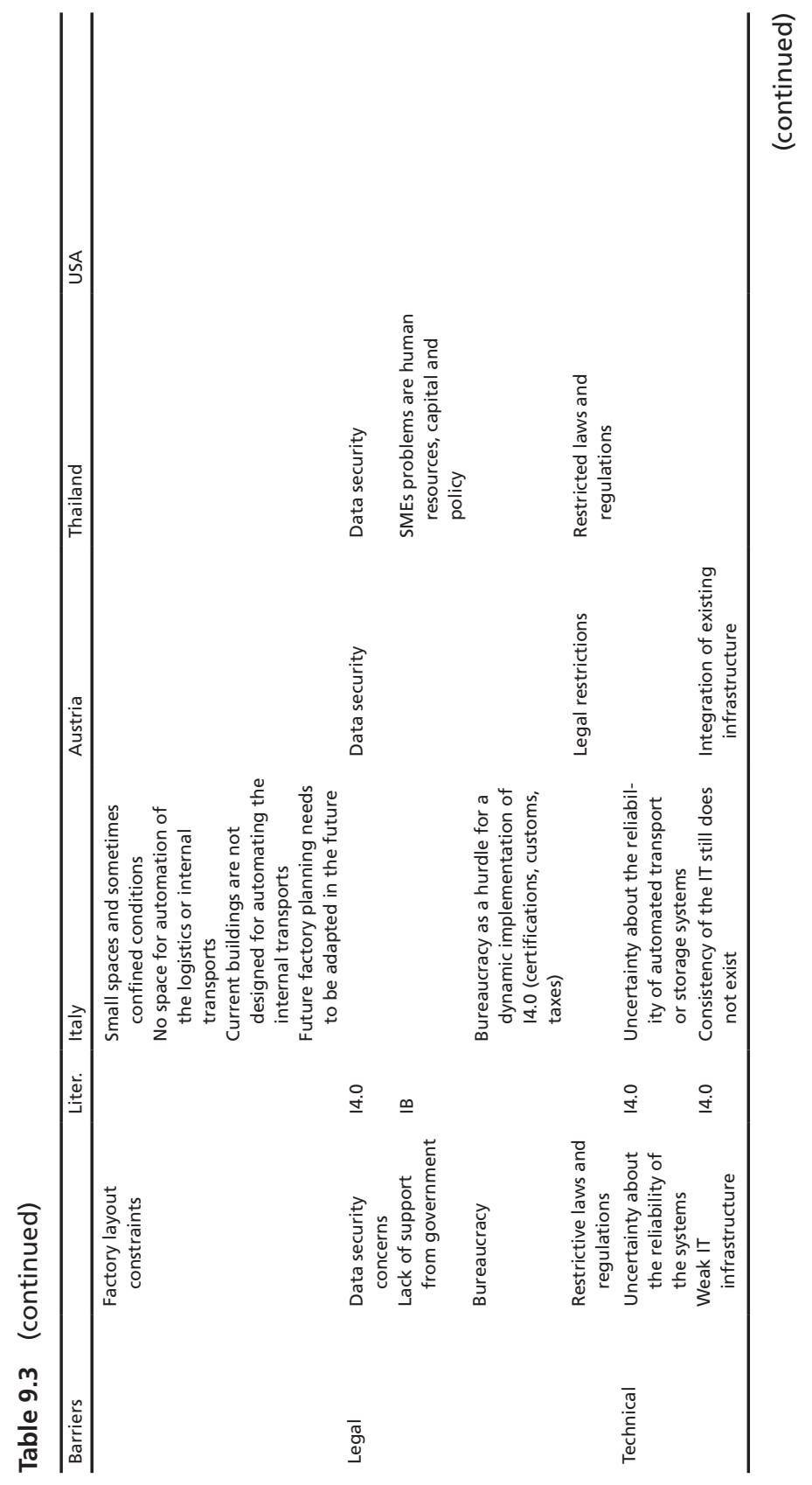




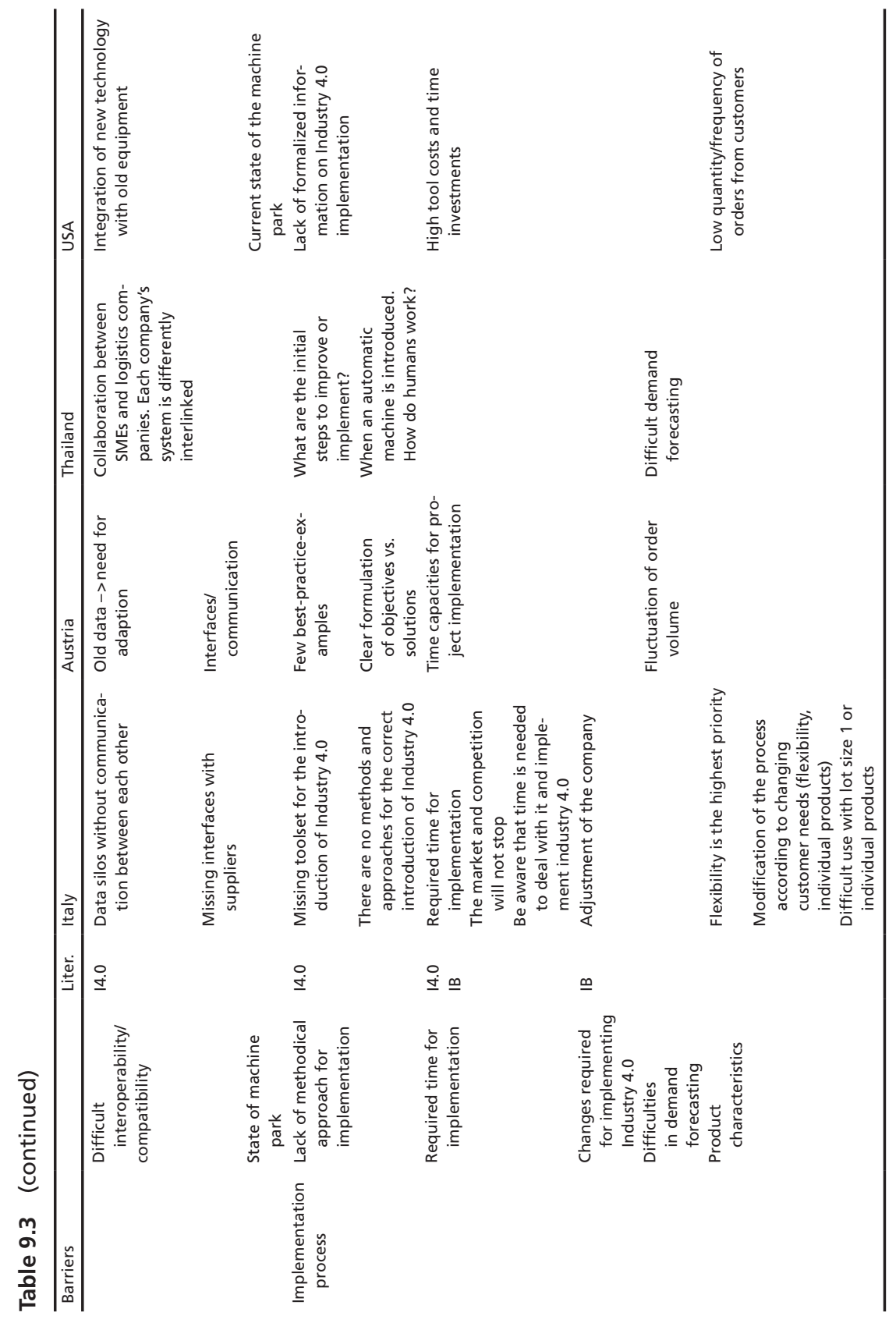


faced by SMEs in measuring the results. Another interesting economicl financial issue reported during the workshops is the value of the product. According to some participants, it is not worth adopting Industry 4.0 if the products produced have a low value. This is particularly true in countries characterized by low labor costs, like Thailand.

Cultural issues (such as lack of support by top management, lack of trust between partners, unsupportive organizational structure, acceptance of employees, and focus on day-to-day operations) appear to be particularly important for Industry 4.0 implementation. Around one-third of the barriers highlighted in the focus groups belong, in fact, to this category. ${ }^{1}$ Among these barriers, we noticed the corporate culture/mentality in Austria, Italy, and Thailand (e.g., the lack of cooperation among functions/departments), employee resistance, and missing top management vision on Industry 4.0 in all four focus groups (due to their poor knowledge of Industry 4.0 and their fear of losing work), and risk aversion in Austria and Thailand. Our focus groups highlighted that the lack of support by top management (clear direction of the company is necessary, lack of communication and transparency, lack of total vision of Industry 4.0) is even more important than the resistance (acceptance) of employees.

As far as competencies/resources barriers are concerned, in all the four analyzed countries, SMEs struggle to find qualified employees with the required technical competences. This means that the lack of technical knowledge is a common factor for SMEs independently of the economic and cultural environment. Another significant barrier highlighted by the focus group organized in Italy is the high coordination effort. This barrier emphasizes the fact that Italian SMEs perceive it to be important to cooperate and develop common solutions for Industry 4.0. US companies reported that they prefer to work autonomously at their own solutions. This could be due to cultural differences between Italy and USA as well as to the different resource endowment of SMEs in the

\footnotetext{
${ }^{1}$ The share has been calculated by dividing the number of barriers included in the category "cultural" by the total number of barriers reported in Table 9.3. Barriers which were repeated in more than one country have been counted only once.
} 
two countries. Another important issue concerns the capital/investments required.

Moving to the legal barriers, another difference among the analyzed countries can be observed. In Austria, Italy, and Thailand bureaucracy and restrictive laws and regulations are seen as a hurdle for the implementation of Industry 4.0 while in the USA, no managers/CEOs reported this issue.

SMEs in Thailand, Italy, and USA highlight that they have different ICT systems and their data are stored in different silos that often do not communicate with each other. Furthermore, they argue that their buildings are not designed for automating internal transports. These technical issues make the implementation of Industry 4.0 more difficult.

Finally, a very important barrier highlighted in the four countries is that a methodical approach for implementing industry 4.0 is missing (implementation process). This is due in part to the novelty of the topic, but also to the fact that each company has its own needs, and these kinds of systems need to be adapted to them.

\subsection{Discussion}

Our empirical analyses (focus groups) confirmed most of the barriers identified by previous literature (e.g., Qiao and Wang 2012; Hatler 2012; Koch et al. 2014; Zawra et al. 2017; Müller et al. 2018) (see Table 9.4).

Previous studies (e.g., Müller et al. 2017) highlighted that SMEs struggle to obtain the resources and tools needed in order to implement Industry 4.0. This has been confirmed by our focus groups, in which participants cited the difficulty of finding skilled employees and the struggle to find the required capital as crucial issues for the implementation of Industry 4.0. These barriers emerged in all four countries (Austria, Italy, Thailand, and USA), meaning that they are independent of the cultural and economic environment.

Another barrier which has been confirmed by the focus group is the lack of a methodical approach for implementation (Liao et al. 2017). CEOs and managers of SMEs located in all four countries reported that 
Table 9.4 Confirmed organizational barriers and problems for Industry 4.0 implementation

\begin{tabular}{ll}
\hline Category & Barrier \\
\hline Economic/financial & High investments required \\
& Lack of clearly defined economic benefit \\
Lultural & Lack of support by top management \\
& Preferred autonomy \\
Competencies/resources & Lack of skilled employees \\
& Lack of technical knowledge \\
& Complexity \\
Legal & Data security concerns \\
Technical & Weak IT infrastructure \\
& Difficult interoperability/compatibility \\
Implementation process & Lack of methodical approach for implementation \\
& High coordination effort \\
\hline
\end{tabular}

a model for implementing Industry 4.0 is missing. The words used during the workshops were: "There are no methods and approaches for the correct introduction of Industry 4.0," "There are limited support resources and a lack of formalized, distilled information on how to implement industry 4.0," "Few Best-Practice-Examples."

A wide set of new barriers have also been identified through our empirical analysis. After significant work to compare the barriers emerging from the focus groups to the ones highlighted by previous literature (even if the terminology used was different), we concluded that 11 new organizational barriers should be considered (see Table 9.5).

Companies report the desire and the need to cooperate with customers and suppliers in order to develop common solutions based on Industry 4.0 (Müller et al. 2017). They also reported that it is very difficult to coordinate themselves with other companies and do joint investments. This can be due to a lack of innovation mentality, or a very rigid organizational structure. Some focus group participants also mentioned that the "real" needs of their customers are sometimes not clear/known and this makes cooperation more difficult.

The second result which emerged from the workshop is that SMEs have some problems in implementing Industry 4.0, because they have to focus on day-to-day operations. This can be also related to the lack of 
Table 9.5 Proposed organizational barriers and problems (not highlighted by previous Industry 4.0 literature)

\begin{tabular}{ll}
\hline Category & Barrier \\
\hline Cultural & Lack of support from customer/supplier \\
& Focus on day-to-day operations \\
& Awareness about the potential of robots \\
& Lack of support from the IT department \\
& Lack of knowledge of Industry 4.0 \\
Competencies/resources & technologies and technical providers \\
& Factory layout constraints \\
Technical & State of machine park \\
Implementation process & Required time for implementation \\
& Changes required for implementing Industry \\
& 4.0 \\
& Difficulties in demand forecasting \\
& Product characteristics \\
\hline
\end{tabular}

monetary resources and to the fact that they do not have a specialized department dedicated to the topic.

Another significant issue is related to the factory layout. This barrier is present only in Italy, especially in South Tyrol, perhaps partly due to the low availability of building land and its high costs. As a result, SMEs cannot easily enlarge their factories. Most of the SMEs are also located in old buildings in which some space constraints are present: small spaces and confined space, no space for automation of logistics and internal transport.

Furthermore, US participants reported that the current state of the machine park is sometimes an obstacle in the introduction of IoT and CPS. There are companies which have already seen the opportunity in this challenge and established a new successful business model, i.e., to modify old machines by equipping them with sensors and connecting them to the network (Wenking et al. 2016).

Finally, a set of new barriers was related to the implementation process (time required for implementation, changes required, difficulties in demand forecasting, and product characteristics). 


\subsection{Conclusions}

The interest devoted by managers, policy-makers, and researchers to the Industry 4.0 topic has grown exponentially during the last few years (Liao et al. 2017). Despite this increasing interest, a methodical approach for implementation is still missing.

The main objective of this study was to shed empirical light on the main organizational requirements for Industry 4.0 implementation in SMEs. We first reviewed the relevant literature. Considering the novelty of the topic, we considered not only the studies on organizational obstacles and barriers for Industry 4.0 implementation but also the broader literature on barriers to innovation. We then conducted some focus groups in four countries (Italy, Austria, Thailand, and USA) in order to empirically validate the list of barriers and issues emerging from the literature review. The focus groups confirmed most of the barriers identified by extant literature (see Table 9.4). They also allowed us to highlight a set of additional barriers not considered by previous studies (see Table 9.5).

We contributed to the scientific debate in at least three significant ways. First, to the best of our knowledge, our study is among the first to empirically highlight a comprehensive set of barriers and problems for Industry 4.0 implementation. This way we might open a debate on a topic that is expected to rise significantly in the next few years. Second, we identified 11 new barriers not highlighted by previous literature. Third, we showed that SMEs perceive a strong need for methodical approaches for Industry 4.0 implementation, thus calling for future research in this area.

Our findings also have strong implications for managers and policy-makers. The identified list of barriers and problems in Industry 4.0 implementation can, for instance, be used by managers to define a set of organizational requirements that should be fulfilled for an efficient and effective implementation of Industry 4.0. Similarly, policy-makers can identify a set of measures - such as incentives, roadmaps, consultancy services - to facilitate SMEs in Industry 4.0 adoption.

The results of our study are characterized by two limitations. First, we adopted a focus group research methodology. Despite several actions being performed to enhance validity and reliability, our findings cannot be generalized to a broader population. Second, our sample consisted of 37 SMEs 
from four countries (Italy, Austria, Thailand, and USA). Caution is therefore needed in extending our results to other contexts. Future research could empirically test our findings on a wider and more heterogenous sample.

\section{References}

Baldwin, J., and Z. Lin. 2002. Impediments to Advanced Technology Adoption for Canadian Manufacturers. Research Policy 31 (1): 1-18.

Cefis, E., and O. Marsili. 2006. Innovation Premium and the Survival of Entrepreneurial Firms in the Netherlands. In Entrepreneurship, Growth, and Innovation, 183-198. Boston, MA: Springer.

Chiesa, V., and F. Frattini. 2011. Commercializing Technological Innovation: Learning From Failures in High-Tech Markets. Journal of Product Innovation Management 28 (4): 437-454.

Culot, G., G. Nassimbeni, G. Orzes, and M. Sartor. 2018. Industry 4.0: Why a Definition Is Not Needed (Just Yet). In Proceedings of the 25th International EurOMA Conference, 51.

D’Este, P., S. Iammarino, M. Savona, and N. von Tunzelmann. 2012. What Hampers Innovation? Revealed Barriers Versus Deterring Barriers. Research Policy 41 (2): 482-488.

Dixit, M., J. Kumar, and R. Kumar. 2015. Internet of Things and Its Challenges. In 2015 International Conference on Green Computing and Internet of Things (ICGCIoT), 810-814. IEEE.

Freel, M.S. 2000. Barriers to Product Innovation in Small Manufacturing Firms. International Small Business Journal 18 (2): 60-80.

Frenkel, A. 2003. Barriers and Limitations in the Development of Industrial Innovation in the Region. European Planning Studies 11 (2): 115-137.

Galia, F., and D. Legros. 2004. Complementarities Between Obstacles to Innovation: Evidence From France. Research Policy 3 (8): 1185-1199.

Geissbauer, R., S. Schrauf, V. Koch, and S. Kuge. 2014. Industrie 4.0Chancen und Herausforderungen der vierten industriellen Revolution. Pricewaterhouse Coopers (PWC) 227: 13.

Geissbauer, R., J. Vedso, and S. Schrauf. 2016. Industry 4.0: Building the Digital Enterprise. PwC, UK.

Grudens-Schuck, N., B.L. Allen, and K. Larson. 2004. Methodology Brief: Focus Group Fundamentals, 12. Ames: Extension Community and Economic Development Publications. 
Hadjimanolis, A. 1999. Barriers to Innovation for SMEs in a Small Less Developed Country (Cyprus). Technovation 19 (9): 561-570.

Hatler, M. 2012. Industrial Wireless Sensor Networks: Trends and Developments. In Tech 59: 9-10.

Heng, S. 2014. Industry 4.0: Upgrading of Germany's Industrial Capabilities on the Horizon. Available at SSRN. https://ssrn.com/abstract=2656608.

Hewitt-Dundas, N. 2006. Resource and Capability Constraints to Innovation in Small and Large Plants. Small Business Economics 26 (3): 257-277.

Holmström, J., M. Holweg, S.H. Khajavi, and J. Partanen. 2016. The Direct Digital Manufacturing Evolution: Definition of a Research Agenda. Operations Management Research 9 (1): 1-10. https://doi.org/10.1007/s12063-016-0106-z.

Hölzl, W., and J. Janger. 2012. Innovation Barriers Across Firms and Countries. WIFO Working Papers (No. 426).

IBM. 2015. Was kann Industrie 4.0? Und können Sie das auch? Available at https:// www-935.ibm.com/services/multimedia/Whitepaper_Industrie_4.0_screen.pdf. Iyer, G.R., P.J. LaPlaca, and A. Sharma. 2006. Innovation and New Product Introductions in Emerging Markets: Strategic Recommendations for the Indian Market. Industrial Marketing Management 35 (3): 373-382.

Jäger, J., O. Schöllhammer, M. Lickefett, and T. Bauernhansl. 2016. Advanced Complexity Management Strategic Recommendations of Handling the 'Industrie 4.0' Complexity for Small and Medium Enterprises. Procedia CIRP 57: 116-121. https://doi.org/10.1016/j.procir.2016.11.021.

Kagermann, H., J. Helbig, A. Hellinger, and W. Wahlster. 2013. Recommendations for Implementing the Strategic Initiative INDUSTRIE 4.0, Securing the Future of German Manufacturing Industry, Final Report of the Industrie 4.0 Working Group. Frankfrut: Forschungsunion.

Kelley, D. 2009. Adaptation and Organizational Connectedness in Corporate Radical Innovation Programs. Journal of Product Innovation Management 26 (5): 487-501.

Koch, V., S. Kuge, R. Geissbauer, and S. Schrauf. 2014. Industry 4.0: Opportunities and Challenges of the Industrial Internet. Strategy \& PwC, UK. Kitzinger, J. 1995. Qualitative Research: Introducing Focus Groups. BMJ 311: 299-302. https://doi.org/10.1136/bmj.311.7000.299.

Krueger, R.A., and M.A. Casey. 2000. Focus Groups: A Practical Guide for Applied Research. Thousand Oaks, CA: Sage.

Liao, Y., F. Deschamps, E.D.F.R. Loures, and L.F.P. Ramos. 2017. Past, Present and Future of Industry 4.0-A Systematic Literature Review and Research Agenda Proposal. International Journal of Production Research 55 (12): 3609-3629. https://doi.org/10.1080/00207543.2017.1308576. 
Lynn, G.S., J.G. Morone, and A.S. Paulson. 1996. Marketing and Discontinuous Innovation: The Probe and Learn Process. California Management Review 38 (3): 8-37.

Madrid-Guijarro, A., D. Garcia, and H. Van Auken. 2009. Barriers to Innovation Among Spanish Manufacturing SMEs. Journal of Small Business Management 47 (4): 465-488. https://doi.org/10.1111/j.1540-627X.2009.00279.x.

Martinez, M.G., and J. Briz. 2000. Innovation in the Spanish Food \& Drink Industry. The International Food and Agribusiness Management Review 3 (2): $155-176$.

McKinsey Digital. 2015. Industry 4.0: How to Navigate the Digitalization of the Manufacturing Sector. https://www.mckinsey.com/ //media/mckinsey/ business \%20functions/operations/our\%20insights/industry\%2040\%20 how $\% 20$ to $\% 20$ navigate $\% 20$ digitization $\% 20$ of $\% 20$ the $\% 20$ manufacturing\%20sector/industry-40-how-to-navigatedigitization-of-the-manufacturing-sector.ashx. Accessed on 20 Dec 2018.

Meißner, A., R. Glass, C. Gebauer, S. Stürmer, and J. Metternich. 2017. Hindernisse der Industrie 4.0-Umdenken notwendig? ZWF Zeitschrift Für Wirtschaftlichen Fabrikbetrieb 112 (9): 607-611. https://doi. org/10.3139/104.111787.

Minetti, R. 2010. Informed Finance and Technological Conservatism. Review of Finance 15 (3): 633-692.

Mohen, P., and L. Roller. 2005. Complementarities in Innovation Policy. European Economic Review 49: 1431-1450.

Mohnen, P., and J.M. Rosa. 2002. Barriers to Innovation in Service Industries in Canada. In Institutions and Systems in the Geography of Innovation, 231250. Boston, MA: Springer and Kluwer Academic Publishers. https://doi. org/10.1007/978-1-4615-0845-8_11.

Müller, J.M., O. Buliga, and K.I. Voigt. 2018. Fortune Favors the Prepared: How SMEs Approach Business Model Innovations in Industry 4.0. Technological Forecasting and Social Change 132: 2-17. https://doi. org/10.1016/j.techfore.2017.12.019.

Müller, J.M., L. Maier, J. Veile, and K.I. Voigt. 2017. Cooperation Strategies Among SMEs for Implementing Industry 4.0. In Proceedings of the Hamburg International Conference of Logistics (HICL), 301-318. https://doi. org/10.15480/882.1462.

Nylander, S., A. Wallberg, and P. Hansson, P. 2017. Challenges for SMEs Entering the IoT World: Success Is About so Much More Than Technology. In Proceedings of the Seventh International Conference on the Internet of Things, 16. https://doi.org/10.1145/3131542.3131547. 
O'Connor, G.C., and R. DeMartino. 2006. Organizing for Radical Innovation: An Exploratory Study of the Structural Aspects of RI Management Systems in Large Established Firms. Journal of Product Innovation Management 23 (6): 475-497.

Orzes, G., E. Rauch, S. Bednar, and R. Poklemba. 2018. Industry 4.0 Implementation Barriers in Small and Medium Sized Enterprises: A Focus Group Study. 2018 IEEE International Conference on Industrial Engineering and Engineering Management (IEEM), 1348-1352. https://doi. org/10.1109/IEEM.2018.8607477.

Otuka, R., D. Preston, and E. Pimenidis. 2014. The Use and Challenges of Cloud Computing Services in SMEs in Nigeria. Proceedings of the European Conference on Information Management and Evaluation 43 (10): 47-55. https://doi.org/10.5281/zenodo.1127458.

Parker, A., and J. Tritter. 2006. Focus Group Method and Methodology: Current Practice and Recent Debate. International Journal of Research \& Method in Education 29 (1): 23-37. https://doi.org/10.1080/01406720500537304.

Qiao, H.S., and G.L. Wang. 2012. An Analysis of the Evolution in Internet of Things Industry Based on Industry Life Cycle Theory. Advanced Materials Research 430: 785-789. https://doi.org/10.4028/www.scientific.net/ AMR.430-432.785.

Riffai, M.M.M.A., K. Grant, and D. Edgar. 2012. Big TAM in Oman: Exploring the Promise of On-line Banking, Its Adoption by Customers and the Challenges of Banking in Oman. International Journal of Information Management 32 (3): 239-250.

Rüßmann, M., M. Lorenz, P. Gerbert, M. Waldner, J. Justus, P. Engel, and M. Harnisch. 2015. Industry 4.0: The Future of Productivity and Growth in Manufacturing Industries. Boston Consulting Group 9 (1): 54-89.

Sandberg, B., and L. Aarikka-Stenroos. 2014. What Makes It so Difficult? A Systematic Review on Barriers to Radical Innovation. Industrial Marketing Management 43 (8): 1293-1305. https://doi.org/10.1016/j. indmarman.2014.08.003.

Schlaepfer, R.C., and M. Koch. 2014. Industry 4.0 Challenges and Solutions for the Digital Transformation and Use of Exponential Technologies. Finance, Audit Tax Consulting Corporate, Zurich, Swiss.

Schröder, C. 2016. The Challenges of Industry 4.0 for Small and Medium-Sized Enterprises. Bonn, Germany: Friedrich-Ebert-Stiftung.

Stewart, D.W., and P.N. Shamdasani. 1990. Focus Groups: Theory and Practice, 20. Sage. https://doi.org/10.2307/3172875. 
Story, V., S. Hart, and L. O’Malley. 2009. Relational Resources and Competences for Radical Product Innovation. Journal of Marketing Management 25 (5-6): 461-481.

Wenking, M., C. Benninghaus, and T. Friedli. 2016. Umsetzungsbarrieren und-lösungen von Industrie 4.0. ZWF Zeitschrift Für Wirtschaftlichen Fabrikbetrieb 111 (12): 847-850.

Weyer, S., M. Schmitt, M. Ohmer, and D. Gorecky. 2015. Towards Industry 4.0-Standardization as the Crucial Challenge for Highly Modular, Multivendor Production Systems. IFAC-Papersonline 48 (3): 579-584.

Wolfe, R., P.M. Wright, and D.L. Smart. 2006. Radical HRM Innovation and Competitive Advantage: The Moneyball Story. Human Resource Management 45 (1): 111-145.

World Economic Forum. 2014. Industrial Internet of Things, Unleashing the Potential of Connected Products and Services. Geneva, Switzerland: World Economic Forum Industrial Internet Survey.

Zawra, L.M., H.A. Mansour, A.T. Eldin, and N.W. Messiha. 2017. Utilizing the Internet of Things (IoT) Technologies in the Implementation of Industry 4.0. In International Conference on Advanced Intelligent Systems and Informatics, 798-808. https://doi.org/10.1007/978-3-319-64861-3_75.

Open Access This chapter is licensed under the terms of the Creative Commons Attribution 4.0 International License (http://creativecommons. org/licenses/by/4.0/), which permits use, sharing, adaptation, distribution and reproduction in any medium or format, as long as you give appropriate credit to the original author(s) and the source, provide a link to the Creative Commons license and indicate if changes were made.

The images or other third party material in this chapter are included in the chapter's Creative Commons license, unless indicated otherwise in a credit line to the material. If material is not included in the chapter's Creative Commons license and your intended use is not permitted by statutory regulation or exceeds the permitted use, you will need to obtain permission directly from the copyright holder.

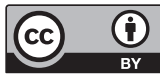

